\title{
PERLINDUNGAN KERJA LAYAK PADA PEKERJAAN ASISTEN RUMAH TANGGA PEREMPUAN DI DESA SOCAH BANGKALAN-MADURA
}

\author{
Miftachul Choir ${ }^{1}$; Anita Kristina ${ }^{2}$ \\ Fakultas Ekonomi \& Bisnis, Universitas Trunojoyo Madura \\ Jln. Raya Telang PO BOX 2 Kamal, Bangkalan-Madura \\ E-mail : anita.kristina@trunojoyo.ac.id \\ diterima: 27/7/2020; direvisi:14/8/2020; diterbitkan: 26/9/2021
}

\begin{abstract}
The purpose of the study was to analyze the decent work protection of female domestic assistant workers. This research was conducted with a qualitative phenomenological approach, analyzed by the inductive method. Data collection was carried out by in-depth interviews with female household assistant actors and their employers in the village of Socah, Bangkalan-Madura. The findings show that there is work hour discrimination that is hours of work not in accordance with the initial agreement, there is workload discrimination that is doing a lot of work beyond the value limit of women, and findings on work protection without insurance. In the end it can be concluded, decent work is said to be socially feasible, because it is presented in work ethics. And discrimination against this work occurs a lot in social relations in the work of this female household assistant
\end{abstract}

Keywords: Work discrimination, Workload, Work Protection, Household Assistant.

\section{PENDAHULUAN}

Konsep pekerjaan layak secara formal telah diakui oleh Organisasi Internasional Buruh (ILO) yaitu melibatkan menciptakan dan mempertahankan peluang untuk pria dan wanita dalam mendapatkan pekerjaan produktif yang didasarkan pada kebebasan, keseteraan dan keamanan martabat manusia diterjemahkan dalam pengukuran pekerjaan layak (ILO, 2013) tersebut memuat: (1). Peluang kerja, (2). Penghasilan yang memadai dan pekerjaan yang produktif, (3). Waktu kerja yang layak, (4). Menggabungkan pekerjaan, keluarga dan kehidupan pribadi, (5). Pekerjaan yang harus dihapuskan, (6). Stabilitas dan keamanan kerja, (7). Kesempatan dan perlakuan yang sama dalam pekerjaan, (8). Lingkungan kerja yang aman, (9). Jaminan sosial, (10). Dialog sosial, pengusaha, dan pekerja. Ke sepuluh indikator ini memuat konsep kualitas ketenagakerjaan standar ILO yaitu pada standar perburuhan internasional pada prinsip dan hak fundamental pada pekerjaan, standarisasi pada penciptaan lapangan kerja, perlindungan sosial dan dialog sosial. Visi ini tentang konsep pekerjaan layak sebagai pengembangan strategis bidang sosial dan tenaga kerja dan jalan menuju penghapusan/meningkatkan layanan pada pekerjaan layak (Kolot \& Herasymenko, 2017 ;Pereira, SA et al, 2019). Layak kerja juga dikontruksi sebagai identifikasi atas perolehan hak-hak dan hubungan kepentingan antara pemberi kerja dan pelaku (Gibb \& Ishaq, 2020).

Pekerjaan layak juga menjadi hak pelaku kerja sektor informal. Beragam persoalan muncul terkait pekerjaan layak pada pekerjaan informal yang dikarenakan tatanan kelembagaan dalam hubungan ketenagakerjaan yang lemah (Abraham et al., 2017; Williams, C.C. and Horodnic, 2019).

Dimensi budaya juga mempengaruhi perlakuan majikan dan lingkungan pada pekerja informal (Junaid et al., 2019). Sementara itu pilihan profesi pada pekerjaan informal memiliki hubungan negatif dengan keseimbangan pemenuhan kebutuhan hidup (Gertsson et al., 2017). Tetapi masih banyak perempuan yang mau bekerja dalam sektor informal, meskipun 


\section{Jurnal Ilmiah Ekonomi dan Bisnis}

Vol. 18. No.2,September 2021 : 109-118

EISSN : $2442-9813$

ISSN : $1829-9822$

sikap sosial budaya masyarakat masih mempengaruhi dalam hubungan kerja dan pembentukan kelayakan kerja (Roomi et al, 2018). Pekerja perempuan banyak yang menjadi subyek atas isu kelayakan kerja ini, karena perempuan yang bekerja pada sektor informal memiliki fleksibiltas jam kerja, dan memiliki prinsip membantu suami (Belwal et al., 2019; Argawala, 2019). Kepatuhan pada aturan kelembagaan informal pada pekerjaan berkontribusi pada ketidaksempurnaan pekerjaan layak, pekerja perempuan sangat patuh pada majikan, dan mereka tidak memiliki kuasa untuk mengatakan tidak (Trentini, 2016). Beberapa persoalan ini memunculkan indikasi adanya upaya eksploitasi dan tidak ada perlindungan kerja, karena resiko dalam hubungan ketenagakerjaan akan ditemui banyak eksploitasi dan rendahnya perlindungan kerja (Banerjee \& Goswami, 2019).

Seringkali pekerja pada sektor informal mempersepsikan pekerjaan layak pekerja asisten rumah tangga yang mereka alami sangat rendah, harapan dan mereka menyelesaikan persoalan ketenagakerjaan sendiri (Fouskas,2017; Pfau-Effinger, 2017). Persepsi ini membentuk keyakinan tidak adanya kepedulian majikan. Asisten rumah tangga perempuan ketika bekerja tidak dibayar, upah yang diberikan hanya berdasarkan sukarela (Mahapatro, 2019), Diskriminasi upah juga terjadi pada pekerja laki-laki dan perempuan (Franca, et al, 2020; Ordine, 2019; Bishnoi, 2020). Distribusi upah yang tidak sama, tidak membawa dampak pada berkurangnya minat perempuan ini untuk tetap bekerja sebagai asisten rumah tangga. Tidak ada kepastian kerja, diantaranya jam kerja, perlakuan adil, dan keseimbangan hubungan kerja antara pekerja dan majikan (Hussain \& Endut, 2018). Tekanan internal dan eksternal dalam lingkungan pekerja juga memunculkan sebuah ketidakadilan (Khan et al., 2019). Hal ini sebagai respon atas reaksi hubungan seimbang dalam hal kekuasaan bertindak dan pengambilan keputusan terkait pekerjaan. Sehingga membuka peluang terjadinya diskriminasi beban kerja juga, yakni pemberian beban kerja yang tidak sesuai perannya (Agarwala, R. And Chun, J, 2018), tetapi juga ini masih ditemui disekitar isu identitas sosial, seperti jenis kelamin, ras, usia dan status sosial (Balasubramanian \& Sarkar, 2020).

Dimensi pekerjaan layak pada penelitian ini didasarkan pada diskriminasi yang terjadi pada lingkup pekerjaan asisten rumah tangga perempuan, yang selama ini diteliti dari aspek persoalan ketenagakerjaan saja. Namun, dalam penelitian ini dimensi pekerjaan layak dilihat dari aspek perlindungan sosial asisten rumah tangga. dilakukan di desa Socah, Bangkalan-Madura. Mayoritas perempuan di sana bekerja sebagai asisten rumah tangga. Peneliti sangat dekat dengan subjek penelitian, sehingga aktivitas atau keseharian pekerjaan yang dilakukan oleh pekerja asisten rumah tangga dirumah majikan banyak diketahui oleh peneliti. Semangat mencari nafkah pada perempuan pedesaan yang bekerja sebagai asisten rumah tangga ini perlu diapreasiasi dengan memberikan kesempatan kerja yang sama, dan juga memberikan keadilan (Abraham et al., 2017). Penelitian ini akan banyak melakukan penyelidikan bagaimana hubungan ketenagakerjaan dalam konsep perlindungan kerja dan layak kerja pada asisten rumah tangga perempuan? Hal ini memuat persoalan diskriminasi jam kerja, beban kerja dan perlindungan kerja. Dengan demikian penelitian ini bertujuan untuk menganalisis perlindungan kerja layak pada asisten rumah tangga perempuan. Implikasi teoritis pada penelitian ini sebagai pengembangan konsep hubungan ketenagakerjaan pekerjaan layak. Secara praktis, penelitian ini mengusulkan atau memberikan masukan agar pembuat kebijakan dapat membuat kebijakan pada perlindungan kerja asisten rumah tangga. Penelitian ini juga memberikan pemahaman pengetahuan terkait pekerjaan layak 
Jurnal Ilmíah Ekonomí dan Bisnis

Vol. 18. No.2,September 2021:109-118 EISSN : $2442-9813$

ISSN : $1829-9822$

sehingga ada perubahan positif terkait persepsi dan mendorong perbaikan perlindungan kerja pada asisten rumah tangga.

\section{TINJAUAN PUSTAKA}

Pekerjaan layak dalam pekerjaan informal merupakan inisiatif yang diprakarsai oleh Organisasi Perburuhan Internasional pada tahun 1999. Inisiatifnya adalah untuk mempromosikan pekerjaan yang layak dan produktif untuk semua orang termasuk perempuan dan anak muda. Pekerjaan Layak melibatkan menciptakan dan mempertahankan peluang untuk pria dan wanita mendapatkan pekerjaan produktif di bawah kondisi kebebasan, kesetaraan, keamanan dan martabat manusia (ILO, 2013). Gagasan ILO 'Pekerjaan Layak' adalah upaya sistematis untuk membuat konsep 'kualitas ketenagakerjaan (Burchell, B.et al, 2014). Pada arsitektur agenda 'Pekerjaan Layak' berisi empat pilar strategis: (1) standar perburuhan internasional serta prinsip dan hak fundamental di tempat kerja; (2) penciptaan lapangan kerja; (3) perlindungan sosial; dan (4) dialog sosial dan tripartisme. Terdapat sepuluh elemen substantif mendukung Kerangka Kerja ILO tentang Pengukuran Pekerjaan yang Layak : (1) Peluang kerja, (2) Penghasilan yang memadai dan pekerjaan produktif, (3) Waktu kerja yang layak, (4) Menggabungkan pekerjaan, keluarga, dan kehidupan pribadi, (5) Pekerjaan yang harus dihapuskan, (6) Stabilitas dan keamanan kerja, (7) Kesempatan dan perlakuan yang sama dalam pekerjaan, (8) Lingkungan kerja yang aman, (9) Jaminan sosial, dan (10) Dialog sosial, perwakilan pengusaha dan pekerja (ILO, 2013). Biasanya dari sepuluh elemen substantif ILO ini lebih sering ditemukan pada pekerjaan sektor informal.

Sektor informal merupakan sektor ekonomi yang terdiri dari unit usaha berskala kecil yang memproduksi serta mendistribusikan barang-barang dan jasa dengan tujuan pokok menciptakan kesempatan kerja dan pendapatan bagi dirinya yang dibatasi oleh faktor kapital, baik fisik maupun keterampilan. Sektor informal diartikan sebagai usaha yang dijalanakan dengan aturan-aturan pribadi, keterampilan sederhana, berproduksi dan melakukan kontrak sendiri terhadap usaha yang dibangun. Dalam aplikasinya, sektor informal adalah bidang usaha yang paling banyak dilakukan oleh masyarakat, karena mudah untuk dilakukan, mudah dimasuki dan tanpa memerlukan modal besar menggunakan teknologi sederhana beroperasi dalam skala kecil, padat karya, selain itu tidak terikat oleh aturan-aturan pemerintahan dan berbagai aturan lainnya.

Selanjutnya, jika dikaitkan dengan pekerjaan layak, maka pekerja informal seyogyanya mendapatkan hak-haknya. Yaitu terutama berkaitan dengan upah/gaji. Jaminan hukum atas upah yang layak tercantum dalam UUD 1945 pasal 28D dan pasal 27 ayat 2 menegaskan bahwa setiap orang berhak mendapatkan upah dan penghidupan bagi kemanusiaan. Juga UU No 13 Tahun 2003 tentang ketenagakerjaan, dimana dalam pasal 88 menyebutkan bahwa setiap buruh berhak memperoleh penghasilan yang layak bagi kemanusiaan dan untuk mewujudkannya pemerintah menetapkan kebijakan pengupahan yang melindungi buruh, diantaranya yaitu upah minimum berdasarkan kebutuhan hidup layak (KHL), upah lembur, struktur dan skala upah yang proporsional, dan upah untuk pembayaran pesangon. Lalu, pada akhirnya pemberian hal yang sama atas dasar jam kerja, pemberian kerja, dan beban kerja yang sama (ILO, 2013).

\section{METODE PENELITIAN}

Fokus penelitian dilakukan pada persoalan perlindungan kerja layak pada pekerjaan asisten rumah tangga perempuan. Jenis data yang digunakan adalah data primer dengan informan sebagai sumber data primer. Penelitian ini dilakukan 
Jurnal Ilmiah Ekonomi dan Bisnís

Vol. 18. No.2,September 2021 : 109-118

EISSN : $2442-9813$

ISSN : $1829-9822$

dengan pendekatan kualitatif

fenomenologi, dianalisis dengan metode induktif. Pengumpulan data dilakukan dengan diawali observasi kemudian dilakukan wawancara mendalam dengan pelaku asisten rumah tangga perempuan dan majikan mereka yang berada di Desa Socah, Bangkalan-Madura. Uji keabsahan data dilakukan melalui uji triangulasi sumber. Kemudian uji kredibilitas melalui eksplorasi hasil didiskusikan dengan beberapa teori/konsep, yakni kelayakan kerja dalam lingkup ketenagakerjaan.

\section{HASIL DAN PEMBAHASAN}

Kesepakatan kerja adalah perjanjian yang dibuat oleh kedua belah pihak antara pengusaha dan pekerja untuk disepakati bersama, begitu pula pada kesepakatan antara majikan dan asisten rumah tangganya. Berikut ini adalah keterangan dari informan majikan mengenai kesepakatan awal kerja :"Kesepakatan awal antara pekerja asisten rumah tangga dan saya sebagai majikan, disepakati bahwa asisten rumah tangga bekerja dimulai pada jam tujuh pagi sampai dengan jam tiga sore, hari kerja dimulai pada hari senin sampai dengan hari sabtu mas, sedangkan untuk beban kerja yang harus dikerjakan oleh asisten rumah tangga yakni memasak, mencuci, menyapu dan membereskan seluruh pekerjaan didalam rumah kami".

Asisten rumah tangga sebagai pekerja dirumah majikan, suka atau tidak suka harus mengikuti apa yang diperintahkan oleh majikan. Jika majikan menyuruh untuk datang lebih pagi maka pekerja asisten rumah tangga juga menyesuaikan. Sebagai bagian dari tanggung jawab bekerja pada sektor informal, dimana sektor informal ini tidak ada aturan resmi mengenai jam kerja dan hal semacam ini bisa dikatakan sebagai diskriminasi. Diskriminasi kerja adalah pembedaan perlakuan atau perlakuan yang tidak adil mengenai jam kerja. Aturan atau kesepakatan mengenai jam kerja yang telah disepakati sebelumnya terpaksa dilanggar atau dikesampingkan karena sesuatu hal. Setiap perbedaan atas kesempatan yang sama dalam pekerjaan dan jam kerja akan berakibat pada kesempatan yang tidak sama. Perlakuan ketidaksamaan antara jam kerja yang disepakati dulu akan juga berakibat pada pengurangan kesempatan mendapatkan perlakuan yang adil. Hal ini yang dirasakan oleh informan: "Sebenarnya dulu disepakati saya mulai kerja jam 7 pagi, tetapi kadang-kadang Ibu (majikan) meminta saya datang lebih pagi. Mau gimana lagi, saya yang butuh, meskipun saya merasa tidak adil, karena sering sekali begitu,"

Istilah diskriminasi biasanya digunakan untuk melukiskan dari pihak mayoritas yang dominan dalam hubungannya dengan minoritas yang lemah. Berikut ini keterangan mengenai jam kerja oleh informan majikan :"Jam kerja pada asisten rumah tangga kami biasanya mulai bekerja pada jam 7 pagi hingga nanti jam 3 sore. Tetapi jika kami memiliki kepentingan atau pada saat kami diharuskan berangkat ke kantor lebih pagi, terpaksa kami panggil asisten rumah tangga untuk bekerja lebih pagi dari biasanya, dan itu tidak terjadi setiap hari mas."

Berdasarkan keterangan informan majikan tersebut, menunjukkan bahwa diskriminasi jam kerja, atau ketidaksesuaian dari kesepakatan awal mengenai jam kerja bagi pekerja asisten rumah tangga perempuan tidak terjadi setiap hari, akan tetapi terjadi ketika pada saat momen atau waktu tertentu saja. Sedangkan berdasarkan keterangan pekerja asisten rumah tangga tentang jam kerja, diungkapkan oleh informan berikut:"Mon tang jam alakoh ngalak bhuru le', lok padha so kesepakadhan otaba parjenjien lambe' ruah teppak kabit alakoh, sajen kannak kadhang sajen lagghu mon mangkat alakoh deri sabellumah". (kalau jam kerja saya sebagai asisten rumah tangga tidak sesuai kesepakatan atau perjanjian dulu ketika awal pertama bekerja. Seiring perjalanan 
waktu, saya terkadang bekerja lebih pagi dari perjanjian sebelumnya).

Berdasarkan keterangan informan tersebut, menunjukkan bahwa diskriminasi jam kerja masih ditemukan dalam pekerjaan asisten rumah tangga. Jam kerja dari minggu ke minggu menciptakan banyak kesulitan untuk pekerja dan keluarga mereka (Finningan, $\mathrm{R}$ and Hunter, 2018). Kesepakatan tentang waktu kerja bagi asisten rumah tangga hanya sebatas kesepakatan biasa. Hal ini dapat dimaknai bahwa kesepakatan yang telah disepakati oleh majikan dan pekerja asisten rumah tangga perempuan dibuat pada saat itu, secara lisan dan tidak tertulis. Aturan mengenai waktu kerja, sudah diatur pada Undang - Undang Nomor 13 tahun 2003 tentang ketenagakerjaan (UUK), dimana sudah diatur waktu kerja didalamnya, bahwa pekerjaan yang dilakukan selama 7 jam kerja/hari atau 40 jam kerja/minggu untuk 5 hari kerja dalam satu minggu. Dan jika jam kerja pekerja melebihi batas tersebut sudah selayaknya seorang pekerja mendapatakan kompensasi tambahan upah sebagai pengganti waktu dan tenaga yang telah dikeluarkan untuk bekerja tambahan. Pekerja telah mendapatkan peningkatan fleksibilitas dalam mengatur kerja dalam ruang dan waktu, itu tanpa batas kerja. Namun, tidak pada pekerjaan asisten rumah tangga, karena mengelola batas antara kerja dan kehidupan pribadi tampaknya menjadi sangat penting jika seseorang ingin lepas secara psikologis kerja selama liburan untuk bersantai dan tidur yang cukup (Mellner et al., 2016).

Temuan lainnya yaitu pekerja asisten rumah tangga yang bekerja sesuai panggilan majikan sebagai berikut: "Kadheng engkok esoro alakoh lek magghi bejenah prei, ye demmah pole engkok ye kodhu mangkat alakoh". (terkadang saya disuruh untuk bekerja dik meskipun waktu libur kerja, ya mau bagaimana lagi saya harus berangkat kerja).
Berdasarkan keterangan informan diatas, bahwa sebenarnya panggilan kerja meskipun dihari libur kerja, adalah berdasarkan kepentingan majikannya. Hal ini bertentangan pada kondisi sosial di lingkungan pekerja, ditemukan bahwa perempuan yang berumur kurang dari 18 tahun tidak boleh dipekerjakan antara pukul 23.00 sampai dengan 07.00. Majikan tidak dapat mempekerjakan perempuan hamil yang menurut dokter membahayakan kesehatan dan keselamatan kandungan dan dirinya apabila bekerja antara pukul 23.00 sampai dengan 07.00. Namun dikarenakan pekerjaan ini dikerjakan secara informal oleh perempuan desa, maka aturan yang berlaku juga berdasarkan hanya pada kesepakatan saja. Hal ini dibenarkan oleh majikan sebagai berikut: "Kan sudah disepakati, tidak ada yang komplain, semua terima saja, berarti saya anggap mereka setuju”

Kesepakatan dalam jam kerja memang tidak diatur secara tertulis, semua tergantung kesukarelaan pekerja saja. Namun, sudah kewajiban majikan untuk memberikan jam kerja yang tepat dan memberikan kesempatan untuk istirahat kepada pekerjanya. Asisten rumah tangga dengan pekerjaan yang bermacam-macam, dan tidak ada terkecuali.

Temuan di lapangan menunjukkan bahwa pekerja asisten rumah tangga pernah mengalami diskriminasi beban kerja atau perlakuan yang tidak adil mengenai beban kerja. Beban kerja yang dimaksud adalah jumlah jam kerja dan banyaknya pekerjaan yang dilakukan asisten rumah tangga. Sebagaimana ungkapan informan sebagai berikut: "alakoh ngalak bhuru rua berre', lessoh, alako eromanah oreng kodhu bisa ngalakoni apa bhei kalakoan e dhelem romanana majikan". (kerja jadi asisten rumah tangga itu berat, capek, jadi asisten rumah tangga harus bisa mengerjakan apa saja pekerjaan rumah tangga dirumah majikan).

Sedangkan menurut keterangan informan majikan adalah sebagai berikut: 
Jurnal Ilmiah Ekonomi dan Bisnis

Vol. 18. No.2,September 2021 : 109-118

EISSN : $2442-9813$

ISSN : $1829-9822$

"Beban kerja pada asisten rumah tangga dirumah saya sebenarnya sama dengan asisten rumah tangga yang lain. Tapi, kalo kami menyelenggarakan hajatan atau acara dirumah, otomatis beban kerja dan jam kerja asisten rumah tangga bertambah".

Pekerja asisten rumah tangga ini cenderung melakukan semua pekerjaan yang ada didalam lingkungan rumah majikan. sehingga beban kerja pekerja asisten rumah tangga dirasa berat dan penuh tanggung jawab. interaksi antara beban kerja tinggi dan ketidakamanan pekerjaan meningkatkan resiko intimidasai di tempat kerja. Kaum wanita hampir selalu mengalami diskriminasi dalam hal memperoleh imbalan atau peningkatan pekerjaan (Todaro. M. P. \& Smith, 2011). Pekerja asisten rumah tangga ini sebenarnya tidak mempunyai spesialisasi dalam bekerja, para pekerja asisten rumah tangga cenderung melakukan semua pekerjaan yang dirasa belum beres. perbandingan gender dan persepsi bias gender terhadap perempuan memediasi sebagian hubungan antara gender dan persepsi diskriminasi gender, sementara perbandingan gender memediasi sepenuhnya hubungan antara kekuatan identifikasi gender dan persepsi diskriminasi gender (Foley et al, 2015). Temuan lain menunjukkan bahwa asisten rumah tangga melakukan banyak hal pekerjaan di rumah majikan, diskriminasi paling sering mengacu pada gender, namun kadang juga menyasar pada basis lain. Untuk mengukur diskriminasi gender, seseorang dapat menggunakan empat indikator, antara lain : (1) tingkat partisipasi angkatan kerja atau rasio kesempatan kerja terhadap penduduk usia kerja perempuan, (2) tingkat pengangguran, (3) perbedaan pendapatan dan tunjangan lainnya, serta (4) distribusi pekerjan terampil, indikator ini akan menunjukkan kesenjangan antara laki laki dan perempuan. Kesenjangan seperti ini dapat terjadi dengan alasan apapun, termasuk diskriminasi, kurangnya latar belakang pendidikan, rendahnya keterampilan dan produktivitas. Diskriminasi gender juga terjadi pada pekerjaan asisten rumah tangga perempuan sebagaimana diungkapkan oleh informan berikut: "Dheddi oreng ngalak bhuru ye kodhu bisa alakoh apa bein kalakoan se bedhe eromanah majikan, kalakoan se kodunah ekalako reng lakek, tape ekalako kiya so engkok contona arabet kebun, ampo toman esoro nyuci mobil". (sebagai pekerja asisten rumah tangga, saya harus bisa melakukan semua pekerjaan rumah dirumah majikan, pekerjaan yang seharusnya dilakukan oleh kaum laki - laki dikerjakan oleh saya kaum perempuan seperti berkebun, bahkan terkadang pernah disuruh untuk mencuci mobil majikannya).

Lima bentuk diskriminasi di tempat kerja diperhitungkan dalam desain pekerjaan berprasangka dan alokasi kerja; penggunaan promosi dan penghargaan yang diskriminatif; perbedaan upah; beban kerja yang meningkat, dan salah kelola instrumen SDM (Palumbo, R. And Manna, 2019). Sekalipun ada aturan formal untuk mempromosikan kesetaraan dan kesetaraan dalam pekerjaan, namun dalam faktor usia dan gender terdapat faktor-faktor diskriminasi di hampir $60 \%$ dari tawaran pekerjaan (Guiterrez-Martinez, I and Olivas-Lujan, 2019). Diskriminasi gender secara positif dikaitkan dengan tuntutan pekerjaan perempuan dan terkait negatif dengan sumber daya pekerjaan mereka. Begitu juga tekait keikutsertaan dalam organisasi pekerja, terdapat diskriminasi keanggotaan perempuan (Dubbelt et al., 2016).

Kehidupan seseorang baik jasmani dan rohani tidak terlepas dari risiko yang mungkin akan suatu saat akan terjadi, baik risiko datangnya dari unsur ketidaksengajaan maupun dari unsur kecerobohan dari individu itu sendiri. Manusia tidak ingin menderita kerugian dan ia selalu berusaha mencegahnya, ataupun setidak-tidaknya mengalihkan risiko yang 
mungkin akan dihadapinya. Jam kerja adalah waktu yang dipersiapkan pekerja dan sebagainya untuk bekerja, atau waktu yang ditentukan untuk melakukan pekerjaan. jam kerja "normal" umumnya diartikan hari kerja dengan jam kerja tersisa untuk rekreasi dan istirahat. Akses ke asuransi lebih mungkin bagi pekerja dengan masa kerja lebih dari dua tahun dan lebih kecil kemungkinannya untuk pekerja yang bekerja lebih dari delapan jam per hari (Banerjee \& Goswami, 2019). Begitu juga pada pernyataan informan sebagai berikut:"Alakoh ngalak buru ye tadek perlindungannah lek, engkok se ngalak buru ye lok mentah bede perlindungannah, Mon sake' ye apareksa dibhi'le'. lok menta ka majikan". (bekerja sebagai asisten rumah tangga ya tidak ada perlindungannya, saya bekerja juga tidak meminta adanya perlindungan. Jika sakit saya periksa sendiri tidak minta ke majikan).

Dari keterangan pekerja asisten rumah tangga tersebut menunjukkan bahwa pekerja asisten rumah tangga belum terlindungi oleh asuransi atau perlindungan kerja lainnya. Sehingga mereka harus menanggung biaya sendiri untuk berobat. Jika pekerja asisten rumah tangga sakit, kesadaran majikan menjenguk dan memberikan uang untuk berobat, serta memberikan waktu untuk istirahat kepada pekerja asisten rumah tangga hingga sembuh dan bisa bekerja kembali. Pihak majikan tidak bisa menerapkan perlindungan kerja kepada pekerja, karena memang belum ada peraturan yang yang mengatur tentang perlindungan kerja bagi pekerja informal. Jaminan kesehatan juga belum diberikan kepada pekerja asisten rumah tangga oleh majikan sebagai bagian dari upah (Hasbullah Thabrany, 2015). Tetapi pada kenyataannya banyak majikan yang tidak mengikutsertakanpekerja rumah tangganya dalam jaminan sosial yang diselenggarakan oleh pemerintah melalui BPJS. Hal itu dikarenakan posisi posisi asisten rumah tangga yang lemah dan sebagai pekerja sektor informal, bekerja hanya dengan perjanjian lisan Temuan atas perlindungan kerja juga didasarkan pada hubungan kerja asisten rumah tangga dan majikan. Asisten rumah tangga adalah orang yang bekerja didalam lingkup rumah majikan, dan majikan adalah orang yang mempekerjakan asisten rumah tangga untuk membantu dalam hal pekerjaan rumah. Sifat hubungan antara asisten rumah tangga dan majikan zaman feodal adalah hubungan yang bersifat patron - client. Namun, sekarang lebih merupakan hubungan yang berorientasi kerja antara dua orang sejajar yang saling membutuhkan, dikarenakan intensitas bertemu sehingga dapat membentuk pola hubungan kerja yang berbeda. Sebagaimana disampaikan oleh informan berikut ini: "Saat pertama kali saya kerja dirumah ini, saya hanya bekerja untuk mendapatkan gaji saja. Lama kelamaan saya bekerja disini saya cukup sering disuruh untuk membawa makanan untuk saya bawa pulang kerumah."

Begitupun dengan informan lainnya, yang bercerita mengenai hubungan kerja asisten rumah tangga dan majikan "Saya mas bekerja disini tidak haya mendapatkan gaji saja. tapi saya juga dikasih oleh-oleh kalau majikan saya pulang kampung, saya juga sering dibawakan makanan, bahkan ketika mau lebaran keluarga saya juga dikasih pakaian oleh majikan saya".

Pernyataan informan ini dapat memberikan gambaran pola hubungan kerja yang terjalin antara asisten rumah tangga dan majikan. Hubungan ini bukan hanya terjalin sebatas pekerja asisten rumah tangga dan majikan saja, akan tetapi hubungan antara keluarga asisten rumah tangga dan keluarga majikan akan terjalin. Perkembangan pola hubungan ini menjadikan kekerabatan tidak hanya dibentuk oleh perkawinan atau hubungan keluarga diantara mereka. dan hubungan yang terjalin baik akan membuat asisten rumah tangga betah dan akan bertahan lama. Asisten rumah tangga dapat bertahan 
Jurnal Ilmiah Ekonomi dan Bisnís

Vol. 18. No.2,September 2021 : 109-118

EISSN : $2442-9813$

ISSN : 1829-9822

lama bekerja di tempat majikan, karena ada komunikasi yang baik antara asisten rumah tangga dan pihak pemberi kerja.

\section{KESIMPULAN DAN SARAN}

Dari penelitian ini dapat disimpulkan bahwa masalah perlindungan kerja layak pada pekerjaan asisten rumah tangga terdapat temuan yaitu diskriminasi kepada asisten rumah tangga perempuan oleh majikan masih terjadi. Diskriminasi atas jam kerja yang tidak sesuai dengan kesepakatan atau perjanjian pada saat awal bekerja, serta pekerja asisten rumah tangga masih bekerja sesuai panggilan majikan. Diskriminasi beban kerja yang dilakukan oleh majikan kepada pekerja asisten rumah tangga adalah pekerja asisten rumah tangga melakukan banyak sekali pekerjaan tanpa adanya spesialisasi, juga pekerjaan yang seharusnya dilakukan oleh seorang laki-laki ini dikerjakan oleh asisten rumah tangga perempuan. Diskriminasi perlindungan kerja pada pekerja asisten rumah tangga dimana pekerja asisten rumah tangga tidak dilindungi oleh asuransi. Dari hal tersebut dapat diberikan saran kepada majikan bahwa, majikan agar lebih menghargai pekerjaan asisten rumah tangga, posisi asisten rumah tangga tidak lagi sekedar pekerjaan yang dianggap rendah, melainkan memandang pekerjaan yang sama dengan pekerjaan yang lainnya. Saran kepada pekerja asisten rumah tangga perempuan, sebelum menyandang profesi asisten rumah tangga dibutuhkan pendidikan atau pelatihan dasar yang menjadi bekal untuk menjalankan profesi sebagai asisten rumah tangga. Keterbatasan penelitian terletak pada fokus pekerjaan layak, maka bagi penelitian lanjutan, yakni pengembangan penelitian dengan subjek pembeda antara asisten rumah tangga laki-laki dan asisten rumah tangga perempuan.

\section{DAFTAR PUSTAKA}

Abraham, A. Y., Ohemeng, F. N. A., \&
Ohemeng, W. 2017. Female Labour Force Participation: Evidence From Ghana. International Journal of Social Economics. 44(11): 1489-1505. https://doi.org/10.1108/IJSE-06-20150159

Agarwala, R. And Chun, J, J. 2018. Gendering Struggles Againts Informal and Precarious Work. (Political Power and Social Theory). Emerald Publishing Limited. 35: 1-28. https://doi.org/10.1108/S0198871920180000035001

Agarwala, R. 2018. From Theory to Praxis and Back to Theory: Informal Workers' Stuggles Againts Capitalism and Patriarchy in India. Gendering Struggles Againts Informal and Precarious Work. Political Power and Social Theory. 35: 29-57. https://doi.org/https://doi.org/10.1108/ S0198-871920180000035002.

Balasubramanian, G., \& Sarkar, S. 2020. Organising Experience of Informal Sector Workers - A road less Travelled. Employee Relations. 42(3): 798-817. https://doi.org/10.1108/ER03-2019-0162

Banerjee, S., \& Goswami, K. 2019. Whether The Industrial Workers of Slums Have Access to Job Insurance? International Journal of Workplace Health Management. 12(3): 102-119 https://doi.org/10.1108/IJWHM-082018-0110

Belwal, S., Belwal, R., \& Al-Hashemi, S. E. 2019. Family Friendly Policies and the Omani Labour Law: What it entails for women employees in Oman. Employee Relations. $\quad 42(2): \quad 315-348$ https://doi.org/10.1108/ER-09-20180245

Bishnoi, S.K. and Kapoor, S. 2020. A case Study on Fair Compensation to hand embroedery Workers in India. Research Journal of Textile and Apparel. $\quad 24(2)$ : 97-110. https://doi.org/https://doi.org/10.1108/ RJTA-07-2019-0030 
Burchell, B., sehnbruch, K., Piasna., A., \& Agloni, N. 2014. The quality of Employment and Decent Work: Definicionts, Methodologies, and ongoing Debates. Journal of Economics. 38(2): 459-477. https://doi.org/10.1093/cje/bet067

Dubbelt, L., Rispens, S., \& Demerouti, E. 2016. Gender discrimination and Job Characteristics. Career Development International. 21(3): 230-245 https://doi.org/10.1108/CDI-102015-0136

Finningan, R and Hunter, S. 2018. Occupational Composition and Racial/Ethnic Inequality in Varying Work Hours in the Great Recession. Race, Identity and Work. (Research in the Sociology of Work). Emerald Publishing Limited. 32: 165-193. https://doi.org/10.1108/S0277283320180000032011

Foley, S., Ngo, H,-Y., Loi, R. Dan Zheng, X. 2015. Gender, Gender Identification and Perceived Gender Discrimination: An Examination of The Mediating Processes in China. Equality, Diversity and Inclusion. 34(8): 650-665. https://doi.org/https://doi.org/10.110 8/EDI-05-2015-0038

Fouskas, T. 2017. (Un)Maid in Greece: Repercussions of Precarious, Lowstatus Work on Family and Community Networks of Solidarity of Migrant Filiphina Live-in Domestik workers and Race Discrimination at Work. (International Perspectives on Equality, Diversity and Inclusion). Emerald Publishing Limited. 6: 225250. https://doi.org/10.1108/S2051233320190000006011

Franca, MTA , Frio, GS and Korzeniewicz, M. 2020. Selfemployment and Wage Difference An analysis for Brazil. International Journal of Social Economics. 47(6): 727-745.
https://doi.org/10.1108/IJSE-05-20190312

Gertsson, N., Sylvander, J., Broberg, P., \& Friberg, J. 2017. Exploring Audit Assistants' Decision to Leave the Audit Profession. Managerial Auditing Journal. $\quad 32(9)$ : 879-898. https://doi.org/10.1108/MAJ-05-20161381

Gibb, S., \& Ishaq, M. 2020. Decent work: What Matters most and Who can Make a Difference?. Employee Relations. 42(4):

845-861. https://doi.org/10.1108/ER-04-20180099

Guiterrez-Martinez, I and Olivas-Lujan, M. 2019. Managing Workplace Inequality in Mexico: An Analysis of Gender, Age, and (Dis)Ability Status. Diversity within Diversity Management (Advanced Series in Management..Emerald Publishing Limited. 22: 175-195. https://doi.org/10.1108/S1877636120190000022010

Hasbullah Thabrany. 2015. Jaminan Kesehatan Nasional. Rajawali Press.

Hussain, A. H. M. B., \& Endut, N. 2018. Do Decent Working Conditions Contribute to Work-life Balance: A Study of Small Enterprises in Bangladesh. Asia Pacific Journal of Innovation and Entrepreneurship. 12(1): 90-104. https://doi.org/10.1108/APJIE-042018-045

ILO. 2013. Decent Work Indicators: Guidelines for Producers and Users of Statistical and Legal Framework Indicators. Proseeding. International Labour Conference.

Junaid, D., He, Z., Yadav, A., \& AsareKyire, L. 2019. Whether Analogue Countries Exhibit Similar Women Entrepreneurial Activities?. Management Decision. 58(4): 759772. https://doi.org/10.1108/MD-062018-0681

Khan, S. I., Bartram, T., Cavanagh, J., 
Jurnal Ilmiah Ekonomi dan Bisnis

Vol. 18. No.2,September 2021 : 109-118

EISSN : $2442-9813$

ISSN : $1829-9822$

Hossain, M. S., \& Akter, S. 2019. "Decent Work" in the Ready-made Garment Sector in Bangladesh: The Role for Ethical Human Resource Management, Trade Unions and Situated Moral Agency. Personnel Review. 48(1): 40-55. https://doi.org/10.1108/PR-01-20180001

Kolot, A., \& Herasymenko, O. 2017. A deficit of Decent Work as a Current Trend in the Development of Social and Labor Sphere in Ukraine. Knowledge and Performance Management. 14(1): 5-18. https://di.org/10.25161/kpm.1(1).01

Mahapatro, S. 2019. Female Employment in India: Determinants of Choice of Sector of Activity. Journal of Economic Studies. 46(3): 748-759 https://doi.org/10.1108/JES-04-2017$\underline{0108}$

Mellner, C., Kecklund, G., Kompier, M., Sariaslan, A., \& Aronsson, G. 2016. Boundaryless Work, Psychological Detachment and Sleep: Does Working "Anytime" Anywhere' Equal Employees are "always on"? New Ways of Working Practices. Advance Series in Management. Emerald Group Publishing Limited. 16: 29-47.

https://doi.org/10.1108/S1877636120160000016003

Ordine, P., Rose, G, and Vella, G. 2019. Employement Protection and Gender gap; Evidence From a Reform of the Italian Labor Market Regulation System. International Journal of Manpower. 41(1): 1-16. https://doi.org/10.1108/IJM-122018-0400

Palumbo, R. And Manna, R. 2019. A portrait of Workplace Discrimination in Italy: Empirical Evidence From a Nationwide Survey. Evidence-Based HRM. 8(1): 92-112. https://doi.org/10.1108/EBHRM-03$\underline{2019-0029}$
Pereira, SA., dos Santos, NR. And Pais, L. 2019. Decent Works Contribution to the Economy for the Common Good. International Jurnal of Organization Analysis. 28(3): 579-593. https://doi.org/10.1108/IJOA-072019-1840

Pfau-Effinger, B. 2017. Informal Employment in the Poor European Periphery. International Journal of Sociology and Social Policy. 37(7/8): 387-399.

https://doi.org/10.1108/IJSSP-0720160080

Roomi, M.A, Rehman, S. And Henry, C. 2018. Exploring the Normatif Context for Women's Entrepreneurship in Pakistan: A Critical Analysis. International Journal of Gender and Entrepreneurship. 10(2): 158-180. https://doi.org/10.1108/IJGE-03-20180019

Todaro. M. P. \& Smith, S. 2011. Pembangunan Ekonomi. Jakarta. Erlangga.

Trentini, C. 2016. Labor Market and Wage Dispersion. Ineaquality After the 20th Century: Paper from the Sixth ECINEQ Meeting. (Research on Economi Inequality). Emerald Publishing Limited. 83-120. https://doi.org/10.1108/S1049258520160000024005

Williams, C.C. and Horodnic, A. V. 2019. Why is Informal Employment More Common in Some Countries? An exploratory Analisys of 112 countries. Employment Relations. 41(6): 14341450. https://doi.org/10.1108/ER-102018-0285

Keputusan Mentri No. 102 Tahun 2004 pasal 3 tentang waktu kerja lembur dan upah kerja lembur

Peraturan Menteri Tenaga Kerja dan Transmigrasi No 7 Tahun 2003

Undang - Undang Republika Indonesia No 13 Tahun 2003, Pasal 1 Ayat 3. Tentang Ketenagakerjaan 